medRxiv preprint doi: https://doi.org/10.1101/2021.06.12.21258794; this version posted June 15, 2021. The copyright holder for this preprint (which was not certified by peer review) is the author/funder, who has granted medRxiv a license to display the preprint in perpetuity. All rights reserved. No reuse allowed without permission.

\title{
Optimized decision support for selection of transoral robotic surgery or (chemo)radiation: Quantified pre-therapy risk stratification for patient-reported and clinician-graded swallowing impairment and toxicity.
}

Mehdi Hemmati, $\mathrm{PhD}^{1}$, Carly Barbon, $\mathrm{PhD}^{2}$, Abdallah S.R. Mohamed, MD, MSc ${ }^{3,4}$., Lisanne V. van Dijk, $\mathrm{PhD}$, Amy C. Moreno, $\mathrm{MD}^{3}$, Neil D. Gross, MD, Ryan P. Goepfort, MD Stephen Y. Lai, MD, PhD ${ }^{2,4}$, Katherine A. Hutcheson, $\mathrm{PhD}^{2,4}$, Andrew Schaefer, $\mathrm{PhD}^{1}$, Clifton D. Fuller, $\mathrm{MD}, \mathrm{PhD}^{1,3,4}$, for the MD Anderson Head and Neck Cancer Symptom Working Group.

1- Department of Computational and Applied Mathematics, William Marsh Rice University, Houston, TX, USA.

2- Department of Head and Neck Surgery, The University of Texas MD Anderson Cancer Center, Houston, TX, USA.

3- Department of Radiation Oncology, The University of Texas MD Anderson Cancer Center, Houston, TX, USA.

4- The University of Texas MD Anderson Cancer Center UTHealth Graduate School of Biomedical Sciences, Houston, TX, USA.

5- Department of Radiation Oncology, University Medical Center- Groningen, Groningen, NL.

\section{Abstract:}

Purpose: To develop a decision-making tool to choose the optimal treatment for oropharyngeal squamous cell cancer (OPSCC) patients who are eligible for primary transoral robotic surgery (TORS) and primary (chemo)radiation therapy with comparable locoregional control and survival.

Methods: Decision tree models were constructed to study two decision-making scenarios, 1) TORS vs. definitive radiation therapy (RT), and 2) TORS vs. definitive chemo(radiation) therapy (CRT) based on well-established objective and subjective swallowing-function instruments, MD Anderson Dysphagia Inventory (MDADI), MD Anderson Symptom Inventory-Head and Neck Module (MDASI-HN), and clinician-rated Dynamic Imaging Grade of Swallowing Toxicity (DIGEST) that measure swallowing-related toxicity pre-therapy, 3-6 months (short-term), and 18-24 months (long-term) after therapy for five treatment cohorts (RT, CRT, TORS, TORS with adjuvant RT, and TORS with adjuvant CRT). The optimal treatment was sought as a function of postoperative extranodal extension (ENE) and/or positive margin (PM) that can trigger the adjuvant therapy. 2D heatmaps were constructed indicating the thresholds of postoperative events likelihoods required for TORS or definitive therapy to become the optimal treatment. Additionally, a risk calculation model was developed to quantify the risk associated with TORS in the settings that estimation of postoperative complications likelihoods may not be available.

Results: Under the first scenario and for short-term measures, MDADI and MDASI instruments indicate the superiority of definitive therapy to TORS at all times, while DIGEST required a maximum of $40 \%$ likelihood for both ENE and PM events to indicate TORS as the optimal treatment. For 18-24 months measures, MDASI indicated TORS as the optimal treatment; however, MDADI- and DIGEST-based long-term measures indicated threshold likelihoods of $90 \%$ and $25 \%$, respectively, for TORS to remain the optimal treatment. For short-term outcomes, TORS resulted in higher toxicity even when the likelihood associated with postoperative tumor resection margin (TM) are extremely low. For higher probability of postoperative TM, all instruments indicated high risk associated with TORS ( $>83 \%)$. For long-term swallowingrelated toxicity, TORS remained the optimal therapy independent from the probability of postoperative TM based on MDASI instrument. However, MDADI-based measure assigned a high risk to TORS (>86\%) when postoperative TM is extremely likely. DIGEST-based measures indicated a very high risk associated with TORS independent from the postoperative TM likelihood (>91\%).

Under the second scenario (TORS vs. definitive CRT), Both MDASI- and MDADI-based short-term measures indicated TORS as the optimal therapy independent from postoperative ENE/PM events. However, according to the DIGESTbased measure, definitive RT remained the optimal therapy when the probability of postoperative ENE and PM events exceed $80 \%$. In this case, TORS was the optimal therapy if both events were not relatively likely $(<55 \%)$. The same result was observed for MDADI and MDASI instruments for long-term measures indicating TORS as the optimal therapy independent from postoperative PM or ENE events. However, the DIGEST measure indicated that TORS is the optimal NOTE: This preprint reports new research that has not been certified by peer review and should not be used to guide clinical practice. 
therapy only if the likelihood of both events are very low $(<20 \%)$. When the postoperative TM is very unlikely $(<10 \%)$, all instruments indicated TORS as the optimal therapy based on short-term outcomes. However, when the postoperative TM is extremely likely ( $>90 \%)$, DIGEST-based measures demonstrated the superiority of definitive CRT once the likelihood of postoperative ENE or PM is, at least, $60 \%$. Long-term measures indicated higher sensitivity to postoperative TM likelihood with both MDADI- and DIGEST-based measures indicating a moderately high risk (> 60\%) with TORS causing higher clinician-rated swallowing toxicity compared to definitive CRT when postoperative TM is extremely likely.

Conclusion: The current study using decision modeling shows proof of concept that in the absence of reliable estimation of postoperative ENE/PM events concurrent with significant postoperative positive margins (i.e., more than $2 \mathrm{~mm}$ ) that can trigger adjuvant therapy, the overall toxicity level incurred by OPSCC patients undergoing TORS may become more severe compared to patients receiving non-surgical treatments thus advocating definitive (C)RT protocols. The results further demonstrated that, when available, the likelihoods of postoperative events triggering postoperative adjuvant therapy must be incorporated when choosing the optimal treatment plan for eligible patients.

\section{Introduction}

Recent studies indicate that the incidence of human papillomavirus associated (HPV+) head-and-neck (HNC) cancer have been on a sharp rise, and the incidence of this malignancy is projected to nearly double by the year $2030 .{ }^{1,2}$ With a yearly incidence of 600,000 cases worldwide, there are 62,000 HNC cases annually in US with an estimated 13,000 deaths ${ }^{3,4}$, this is driven by the endemic rise of oropharyngeal squamous cell cancer (OPSCC) ${ }^{5}$. Historical OPSCC surgical treatment for OPSCC involved open surgery such as transmandibular and transcervical pharyngotomy, which are associated with significant functional morbidity such as dysphagia. ${ }^{6-8}$ To reduce postoperative morbidity, high-dose radiation therapy (RT) in combination with chemotherapy became the standard organ-preserving approach, offering comparable locoregional control and survival. However, nonsurgical (chemo) radiation therapy (CRT) treatments also put the patient at risk for multiple post-treatment toxicities, including radiation-associated dysphagia.

Transoral robotic surgery (TORS) is a surgical approach that was approved by FDA in 2009 and involves minimal disturbance to critical nerves and swallow musculature of the laryngopharynx, thus promising superior acute postoperative swallowing outcomes compared to traditional open surgical approaches ${ }^{9}$ and therapeutic nonsurgical organ preservation regimens in OPSCC ${ }^{10}$ as reported in prospective cohort studies. ${ }^{11-14}$ Proponents of a primary TORS approach further cite potential for de-escalation protocols or avoidance of of adjuvant therapies, altogether as a major functional advantage of TORS. ${ }^{10}$ Despite TORS promise, it is reported that only 9-27\% of patients treated with frontline TORS avoid postoperative adjuvant RT, and 34-45\% avoid adjuvant CRT. ${ }^{10}$ As probabilistic outcomes of TORS, postoperative positive margins (PM) or pathological extranodal extensions (ENE) indicate increased risk of recurrence, and necessitate adjuvant (C)RT (Figure 1) with resultant short- and long-term radiation associated toxicities. ${ }^{14,15}$ In a recent study on a cohort of low- and intermediate-risk OPSCC patients receiving definitive (C)RT and TORS (possibly followed by adjuvant therapy), swallowing outcomes (at 3-6 months post-treatment) were reported to be similar regardless of the primary treatment modality. ${ }^{14}$ This suggests that patients undergoing TORS, even when followed by adjuvant therapy, may not incur less severe dysphagia compared to receiving definitive (chemo) radiation therapy as the primary treatment modality.

At present, the relative selection criteria for surgery are primarily qualitative and subjective physician assessments. Studies suggest that, at least in current practices, physicians are quite poor at predicting the necessity of adjuvant therapy based on pre-surgical or imaging risk features. This leaves the provider and patient with an upfront pre-therapy choice: choose

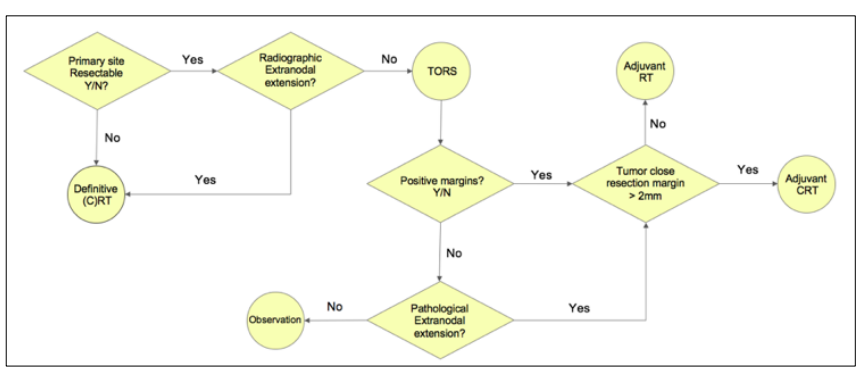

Figure 1: The underlying process for determining the eligibility of the patient for TORS and its probabilistic outcomes definitive (C)RT with known quantized patient-specific toxicity risk probability $O R$ choose an a priori quantifiable toxicity risk of surgery AND an undefined probability of the risk toxicity of adjuvant therapy. The premise of this study is to define, the proportional likelihood of surgical risk features (and resultant indication for adjuvant therapy-associated toxicity) and? mathematically optimal decision making? between primary therapies: (chemo)RT or TORS. Put simply, we address the question of how numerically confident the surgeon and radiation 
oncologist must be in the risk of pre-treatment pathologic margin positivity or extranodal extension be to rationally select TORS for the purposes of minimizing toxicity (assuming equivalent locoregional control) [REF ORATOR, ECOG 3311].

The primary focus of the present study was to develop a decision support tool that aids in selecting the best primary treatment protocol by incorporating the likelihood of postoperative PM and/or ENE to quantify both overall therapy-related discomfort level and swallowing function impairment as short- and long-term toxicities, using an existing prospective dataset. The aims of this study were as follows: 1) to quantify the swallowing-related toxicity levels of definitive therapies (chemo RT) and TORS based on subjective and objective instruments using short-term and long-term assessments of toxicities, and 2) to determine the required confidence level of likelihood of ENE/PM to in order to determine the optimal primary therapy and its' associated risk level. To achieve this aim, we incorporate the quantified expected value of swallowing-related outcomes of each primary treatment based on probabilistic postoperative PM and/or ENE events. This is the first application of decision analysis, a widely established tool for decision making in uncertain environments. We use this tool to quantify the risk of postoperative swallowing-related toxicities and the impact on quality of life, measured using highly reliable functional endpoints frequently used in OPSCC.

\section{Methods}

\section{Study Design}

This secondary analysis was conducted using prospective registry data from the MD Anderson Oropharynx Cancer Registry (PA14-0947) Patient-Reported Outcomes and Function (PROF) Core. The PROF registry enrolls all consenting OPSCC/HNC patients at the University of Texas MD Anderson Cancer Center (MDACC) beginning in March 2015. The sample for this secondary analysis included patients enrolled on PA14-0914 from March 2015 to September 2019. Eligibility criteria were as follows: (1) cancer of the oropharynx, and (2) TORS or RT as primary treatment approach at MDACC. All primary treatment was determined by Multidisciplinary Tumor Board. Data analysis occurred under approval of the Institutional Review Board (protocol PA11-0809). ${ }^{14}$

\section{Demographics}

Demographics and treatment characteristics of the cohort are listed in Table $1 .{ }^{14}$

\section{Toxicity Measures}

Prospective collection of clinician- and patient-graded outcome measures occurred at routine timepoints. The MD Anderson Dysphagia Inventory (MDADI) is a patient-administered 20-item questionnaire that evaluates the impact of dysphagia on quality of life. The MDADI includes one question regarding global function and 19 items that focus on the physical, emotional and functional aspects of swallowing, which are pooled and averaged to obtain a composite score (varying from 20 (poor swallowing-related quality of life) to 100 (optimal swallowing-related quality of life)) ${ }^{16}$. The MD Anderson Symptom Inventory-Head and Neck Module (MDASI-HN) score as a validated multi-symptom inventory of patientreported swallowing and chewing difficulties based on scores varying from 0 (symptom not present) to 10 (highest imaginable severity of the symptom) and represents a generalizable pan-symptom toxicity metric ${ }^{17}$. Lastly, the Dynamic Imaging Grade of Swallowing Toxicity (DIGEST) as a validated and reliable objective tool that measures the presence and severity of pharyngeal dysphagia. The DIGEST parallel's with CTCAE criteria for toxicity reporting Grade 0 (no pharyngeal dysphagia), 1 (mild), 2 (moderate), 3 (severe), and 4 (life-threatening dysphagia). ${ }^{14,18}$ The study was conducted using multiple instruments to avoid risk/decision calibration predicated only based on a subset of the patient toxicity profile, thus accounting for inter-therapy differential toxicity.

\section{Measures}

A total of six measures were developed for this study as follows: each instrument was assessed for all treatment cohorts (TORS, RT alone, CRT alone, TORS with adjuvant RT (TORS+RT), TORS with adjuvant CRT (TORS+CRT)) pre-therapy (baseline), 3-6 months and 18-24 months after primary treatment (Table 2). For each cohort, MDADI-based and MDASIbased absolute short-term deterioration in swallowing function $\left(\Delta_{S}^{\mathrm{MDADI}}\right.$ and $\left.\Delta_{S}^{\mathrm{MDASI}}\right)$ were defined as the reduction in MDADI baseline score and the increment in MDASI baseline score, respectively, within 3-6 months. MDADI-based and MDASI-based absolute long-term deterioration in swallowing function $\left(\Delta_{L}^{\text {MDADI }}\right.$ and $\Delta_{L}^{\text {MDASI }}$ ) were defined analogously with respect to 18-24 months scores. For each treatment cohort, DIGEST-based short-and long-term deteriorations in swallowing functions ( $\boldsymbol{D}^{\text {DIGEST }}$ and $\boldsymbol{R}^{\text {DIGEST }}$ ) were calculated as the fraction of baseline population whose DIGEST baseline 
medRxiv preprint doi: https://doi.org/10.1101/2021.06.12.21258794; this version posted June 15, 2021. The copyright holder for this preprint (which was not certified by peer review) is the author/funder, who has granted medRxiv a license to display the preprint in perpetuity. All rights reserved. No reuse allowed without permission.

grades evolved into any worse grade within 3-6 and 18-24 months after receiving therapy, respectively. (Online Supplements A1-A3).

Table 1: Characteristics of the 257 Patients With Low- to Intermediate-Risk Oropharyngeal Cancer Included in the Study ${ }^{14}$

\begin{tabular}{|c|c|c|c|c|}
\hline Characteristic & $\begin{array}{l}\text { All Patients } \\
(\mathbf{N}=\mathbf{2 5 7})\end{array}$ & $\begin{array}{c}\text { Primary } \\
\text { TORS }(n=75)\end{array}$ & $\begin{array}{l}\text { Primary RT } \\
(\mathbf{n}=182)\end{array}$ & $\begin{array}{c}\text { Effect Size } \\
(95 \% \text { CI })\end{array}$ \\
\hline Age at primary treatment start, mean (SD), y & $59.54(9.07)$ & $58.70(9.60)$ & $59.89(8.84)$ & NA \\
\hline \multicolumn{5}{|l|}{ Sex } \\
\hline Female & $35(13.6)$ & $10(13.3)$ & $25(13.7)$ & \multirow{2}{*}{ NA } \\
\hline Male & $222(86.4)$ & $65(86.7)$ & $157(86.3)$ & \\
\hline \multicolumn{5}{|l|}{ Primary tumor site } \\
\hline Tonsil & $135(52.5)$ & $38(50.7)$ & $97(53.3)$ & \multirow{3}{*}{ NA } \\
\hline BOT & $116(45.1)$ & $34(45.3)$ & $82(45.0)$ & \\
\hline GPS & $6(2.3)$ & $3(4.0)$ & $3(1.6)$ & \\
\hline \multicolumn{5}{|l|}{ Clinical T stage of primary tumor (AJCC Staging Manual, 7th ed.) } \\
\hline 1 & $124(48.2)$ & $40(53.3)$ & $84(46.2)$ & \multirow{3}{*}{ NA } \\
\hline 2 & $126(49.0)$ & $34(45.3)$ & $92(50.6)$ & \\
\hline 3 & $7(2.7)$ & $1(1.3)$ & $6(3.3)$ & \\
\hline Baseline primary tumor volume, median (range), $\mathrm{cm}^{3}$ & $\begin{array}{c}6.50 \\
(0.30-29.30)\end{array}$ & $\begin{array}{c}5.15 \\
(0.30-21.90)\end{array}$ & $\begin{array}{c}6.95 \\
(0.50-29.30)\end{array}$ & $\begin{array}{c}0.18 \\
(0.04-0.29)\end{array}$ \\
\hline \multicolumn{5}{|l|}{ Clinical N stage of primary tumor (AJCC Staging Manual, 7th ed) } \\
\hline 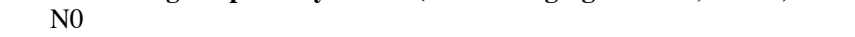 & $50(19.5)$ & $31(41.3)$ & $19(10.4)$ & \multirow{4}{*}{$\begin{array}{l}0.40(0.27- \\
0.51)\end{array}$} \\
\hline N1 & $35(13.6)$ & $15(20.0)$ & $20(11.0)$ & \\
\hline $\mathrm{N} 2 \mathrm{a}$ & $19(7.4)$ & $5(5.3)$ & $15(8.2)$ & \\
\hline $\mathrm{N} 2 \mathrm{~b}$ & $153(59.2)$ & $25(33.3)$ & $128(70.3)$ & \\
\hline Induction Chemotherapy & $21(8.2)$ & $4(5.3)$ & $17(9.3)$ & NA \\
\hline Radiotherapy & $219(85.2)$ & $37(49.3)$ & $182(100$ & NA \\
\hline Concurrent chemotherapy and radiotherapy & $162(63.0)$ & $15(20.0)$ & $147(80.8)$ & NA \\
\hline Radiotherapy dose, median (range), cGy & $\begin{array}{c}6996 \\
(6000-7000)\end{array}$ & $\begin{array}{c}6000 \\
(5000-6996)\end{array}$ & $\begin{array}{c}6996 \\
(6000-7000)\end{array}$ & $\begin{array}{c}0.61 \\
(0.52-0.69)\end{array}$ \\
\hline \multicolumn{5}{|l|}{ Radiotherapy laterality } \\
\hline No radiotherapy & $38(14.8)$ & $38(50.7)$ & 0 & \multirow{3}{*}{$\begin{array}{c}0.67 \\
(0.58-0.75)\end{array}$} \\
\hline Unilateral & $54(21.0)$ & $17(22.7)$ & $37(20.3)$ & \\
\hline Bilateral & $165(64.2)$ & $20(26.7)$ & $145(49.7)$ & \\
\hline Proton radiation therapy & $44(20.1)$ & $5(13.5)$ & $39(21.4)$ & NA \\
\hline Neck dissection & $93(36.2)$ & $75(100)$ & $18(9.9)$ & $\begin{array}{c}0.85 \\
(0.79-0.91)\end{array}$ \\
\hline \multicolumn{5}{|l|}{ Baseline DIGEST score } \\
\hline 0 & $200(80.6)$ & $53(73.6)$ & $147(83.3)$ & \multirow{4}{*}{$\begin{array}{c}0.13 \\
(0.0-0.22)\end{array}$} \\
\hline 1 & $44(17.7)$ & $16(22.2)$ & $28(16.1)$ & \\
\hline 2 & $4(1.6)$ & $3(4.2)$ & $1(0.6)$ & \\
\hline 3 & 0 & 0 & 0 & \\
\hline \multicolumn{5}{|l|}{ Baseline MDADI global score } \\
\hline 40 & $7(3.0)$ & $3(4.6)$ & $4(2.4)$ & \multirow{4}{*}{ NA } \\
\hline 60 & $5(2.1)$ & $2(3.0)$ & $3(1.8)$ & \\
\hline 80 & $42(17.9)$ & $12(18.2)$ & $30(17.6)$ & \\
\hline 100 & $181(77.0)$ & $49(74.2)$ & $132(78.1)$ & \\
\hline Baseline MDADI composite score, median (range) & $\begin{array}{c}95.79 \\
(54.74-100)\end{array}$ & $\begin{array}{c}94.74 \\
(54.74-100)\end{array}$ & $\begin{array}{c}95.79 \\
(57.89-100)\end{array}$ & NA \\
\hline Baseline MDADI physical score, median (range) & $100(45-100)$ & $100(45-100)$ & $100(55-100)$ & NA \\
\hline Baseline MDADI emotional score, median (range) & $\begin{array}{c}86.67 \\
(43.33-100)\end{array}$ & $\begin{array}{c}86.67 \\
(43.33-100)\end{array}$ & $\begin{array}{c}86.67 \\
(56.67-100)\end{array}$ & NA \\
\hline Baseline MDADI functional score, median (range) & $100(64-100)$ & $100(68-100)$ & $100(64-100)$ & NA \\
\hline $\begin{array}{l}\text { Baseline MDASI-HN swallowing symptom severity item score, median } \\
\text { (range) }\end{array}$ & $0(0-9)$ & $0(0-3)$ & $0(0-9)$ & NA \\
\hline \multicolumn{5}{|l|}{ Baseline MDASI-HN swallowing symptom severity item score category } \\
\hline None & $133(68.6)$ & $24(72.7)$ & 109 (67.7) & \multirow{3}{*}{ NA } \\
\hline Mild & $56(28.9)$ & $9(27.3)$ & $47(29.2)$ & \\
\hline Moderate to severe & $5(2.6)$ & 0 & $5(3.1)$ & \\
\hline Baseline MDASI-HN choke score, median (range) & $0(0-8)$ & $0(0-8)$ & $0(0-7)$ & NA \\
\hline \multicolumn{5}{|l|}{ Baseline MDASI-HN choke score category } \\
\hline None & $156(80.0)$ & $30(88.2)$ & $126(78.3)$ & \multirow{3}{*}{ NA } \\
\hline Mild & $35(18.0)$ & $3(8.8)$ & $32(19.9)$ & \\
\hline Moderate to severe & $4(2.0)$ & $1(2.9)$ & $3(1.9)$ & \\
\hline
\end{tabular}




\section{Statistical Analysis}

This study was based on a published analysis conducted by Hutcheson et al. ${ }^{14}$ using the same patient cohort . Further, for each treatment cohort, bootstrapping-based resampling ${ }^{19}$ was applied to mitigate the effects of unequal sample sizes across treatment cohorts $(n=10,000)$. For MDADI and MDASI scores, bootstrapping was employed based on the empirical distribution computed from the frequency of observed scores. The values of $\Delta_{S}^{M D A D I}, \Delta_{L}^{M D A D I}, \Delta_{S}^{M D A S I}$, and $\Delta_{L}^{M D A S I}$ were calculated using bootstrapped datasets for each treatment cohort. For DIGEST grades, bootstrapping was employed based on the assumption that the evolution of baseline grades into 3-6 months and 18-24 months grades follow multinomial distribution based on the incidence reported in Table C1 (Online Supplement C). Using the bootstrapped dataset, the values of $R^{D I G E S T}$ and $D^{\text {DIGEST }}$ were calculated. Table 2 provides the bootstrap-generated measures.

\footnotetext{
Table 2: MDADI, MDASI, and DIGEST pre- and post-bootstrapping scores pre-therapy (baseline), within 3-6 months, and within 18-24 months post-therapy; for DIGEST, total number of cases (bold) and total number of cases whose baseline grades have evolved into inferior grades. $\triangle_{S}^{M D A D I}, \Delta_{L}^{M D A D I}$ : MDADI-based absolute short- and long-term deterioration; $\triangle_{S}^{M D A S I}, \Delta_{L}^{M D A S I}$ : MDASI-based absolute short- and long-term deterioration; $D^{D I G E S T}, R^{\text {DIGEST }}$ : DIGEST-based absolute short- and long-term deterioration in swallowing function.
}

\begin{tabular}{|c|c|c|c|c|c|}
\hline Instrument & CRT & RT & $\begin{array}{l}\text { TORS+ } \\
\text { CRT }\end{array}$ & $\begin{array}{l}\text { TORS+ } \\
\text { RT }\end{array}$ & TORS \\
\hline \multicolumn{6}{|l|}{ MDADI } \\
\hline Baseline (mean) & 93.26 & 87.17 & 94.04 & 90.18 & 88.69 \\
\hline 3-6 Months & 81.14 & 82.02 & 82.89 & 83.80 & 82.55 \\
\hline 18-24 Months & 86.56 & 81.98 & 85.16 & 88.28 & 86.05 \\
\hline Absolute short-term deterioration $\Delta_{S}^{\mathrm{MDADI}}$ (Bootstrapped) & 12.1 & 5.34 & 11.27 & 6.43 & 6.3 \\
\hline Absolute long-term deterioration $\Delta_{L}^{\mathrm{MDADI}}$ (Bootstrapped) & 6.71 & 5.25 & 8.81 & 2.05 & 2.57 \\
\hline \multicolumn{6}{|l|}{ MDASI } \\
\hline Baseline (mean) & 0.47 & 0.99 & 0.59 & 0.32 & 0.81 \\
\hline 3-6 Months & 1.43 & 1.37 & 1.09 & 0.91 & 1.20 \\
\hline 18-24 Months & 0.99 & 1.35 & 0.62 & 0.54 & 0.93 \\
\hline Absolute short-term deterioration $\Delta_{S}^{\mathrm{MDADI}}$ (Bootstrapped) & 0.95 & 0.38 & 0.51 & 0.59 & 0.39 \\
\hline Absolute long-term deterioration $\Delta_{L}^{\mathrm{MDADI}}$ (Bootstrapped) & 0.51 & 0.36 & 0.05 & 0.22 & 0.12 \\
\hline \multicolumn{6}{|l|}{ DIGEST } \\
\hline 3-6 Months incidence with worsen grade & $60(120)^{*}$ & $10(\mathbf{2 3})$ & $4(\mathbf{1 0})$ & $11(\mathbf{1 6})$ & $5(24)$ \\
\hline 18-24 Months incidence with worsen grade & $23(66)$ & $3(11)$ & $3(6)$ & $7(7)$ & $1(\mathbf{1 4})$ \\
\hline Absolute short-term deterioration $\mathrm{D}^{\text {DIGEST }}$ (Bootstrapped) & 0.5 & 0.44 & 0.4 & 0.69 & 0.21 \\
\hline $\begin{array}{l}\text { Absolute long-term deterioration } \mathrm{R}^{\mathrm{DIGEST}} \text { (Bootstrapped) } \\
\text { : indicates number of patients with worsen condition out of all patients. }\end{array}$ & 0.35 & 0.27 & 0.5 & 1.00 & 0.07 \\
\hline
\end{tabular}

\section{Decision Tree Analysis}

The aim of this study is to seek the confidence level suggested the clinical team abide by with respect to the likelihood of postoperative ENE/PM for TORS (definitive (C)RT) to suggest the optimal primary treatment, i.e., to outperform definitive (C)RT (TORS) in terms of expected swallowing-related toxicity level. An expected-value decision tree was constructed following the clinical flow depicted in Figure 1 allowing the measure-based comparison of definitive (C)RT having deterministic outcomes and TORS having probabilistic outcomes (Figure 2). As one of the most common decision support tools for medical decision making, decision trees are extremely efficient in terms of implementing medical guidelines for scenarios with probabilistic outcomes to determine the optimal decision based on of expected value of the outcomes. ${ }^{20}$

The decision tree model was constructed under two distinct scenarios, 1) TORS vs. definitive RT, and 2) TORS vs. definitive CRT, based on the assumption that the patients in each scenario are eligible for both surgical and definitive therapies with comparable locoregional control and survival. For each scenario, the decision model was analyzed for each measure: using the collected measure values (Table 2), the expected value of TORS was calculated as a function of postoperative ENE and PM likelihoods ( $\boldsymbol{p}_{N}^{+}$and $\boldsymbol{p}_{M}^{+}$, respectively, ranging from 0 to 1 ) based on the assumption that when an adjuvant therapy is required, it is equally likely that the patient will undergo adjuvant RT or adjuvant CRT. (Sensitivity analysis was performed to study the effects of this assumption as reported in Online Supplement B.) 


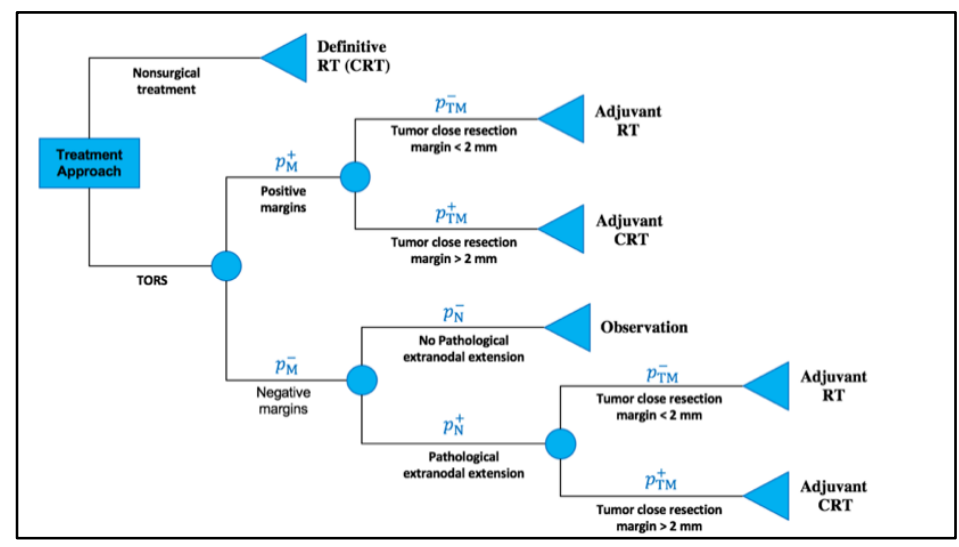

Figure 2: General decision Tree for TORS decision making; scenario 1: definitive RT vs. TORS; scenario 2: CRT vs. TORS; $\left(p_{M}^{+}\left(p_{M}^{-}\right)\right.$: probability of having (not having) positive margins after surgery; $\left(p_{N}^{+}\left(p_{N}^{-}\right)\right.$: probability of having (not having) extranodal extension after surgery; $\left(p_{T M}^{+}\left(p_{T M}^{-}\right)\right.$: probability of having tumor resection margin of more (less) than $2 \mathrm{~mm}$ after surgery

In each scenario, the optimal choice between TORS and the definitive therapy was made based on the observation that for both short- and long-term swallowing-related toxicity levels, the treatment protocol having lower expected value is more favorable. For each scenario and for each short-or long-term measure, the cut-off value for TORS $\left(\boldsymbol{c}_{S}, \boldsymbol{c}_{\boldsymbol{L}}\right)$ was computed as the highest possible expected measure value of TORS for which TORS remains the optimal treatment.

The results of decision tree analysis were demonstrated as $2 \mathrm{D}$ heatmaps, for each measure, revealing the combination of probability values for postoperative ENE and PM events for which TORS results in lower swallowing-related toxicity, thus becoming the optimal treatment. The heatmaps were also employed to derive individual postoperative ENE and PM likelihoods for which definitive therapy becomes the optimal treatment having lower swallowing-related toxicity level. Finally, to account for the inherent difficulty in pre-therapy estimation of postoperative ENE/PM likelihoods, measure-based risk associated with TORS $(\boldsymbol{r})$ were developed as the fraction of possible combination of postoperative ENE and PM likelihoods for which definitive therapy becomes the optimal choice compared to TORS.

\section{Results}

\subsection{TORS vs. definitive RT (Scenario 1)}

\subsubsection{Short-term (3-6 month) outcomes}

The decision tree analysis using both MDADI- and MDASI-based measures implied that definitive RT remains the optimal treatment protocol for any postoperative ENE and PM likelihoods (Figure 3). As evidenced by measure values in Table 2, this is justified based on the observation that the short-term MDADI- and MDASI-based swallowing-related toxicities of TORS $\left(\Delta_{S}^{\mathrm{MDADI}}\right.$ and $\Delta_{\mathrm{S}}^{\mathrm{MDASI}}$, respectively) were always more severe compared to definitive RT. According to the DIGESTmeasure (presence and severity of dysphagia), if the likelihood associated with either ENE or PM is, at least, $75 \%$, definitive RT remains the optimal treatment. For cases in which the likelihood of neither ENE or PM is more than 40\%, TORS was the optimal treatment. Further, in the absence of pre-therapy details regarding ENE or PM likelihood, TORS risk level was at least $65 \%$ (according to DIGEST), and surgery was not recommended based on MDADI- and MDASI-based measures.
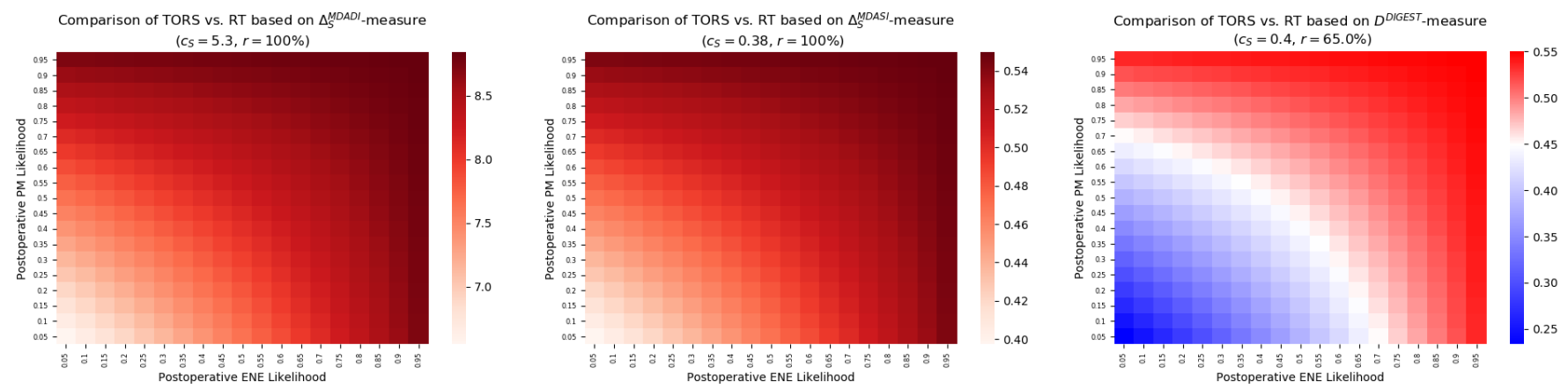

Figure 3: Expected deterioration in swallowing function due to TORS and definitive RT based on short-term measures (left) MDADI, (center) MDASI, (right) DIGEST. $\triangle_{S}^{M D A D I}$ : MDADI-based absolute short-term deterioration; $\triangle_{S}^{M D A S I}$ : MDASI-based absolute short-term deterioration; $D^{\text {DIGEST }}$ : DIGEST-based absolute short-term deterioration in swallowing function; $c_{S}$ : cut-off value for TORS; and $r$ : risk associated with TORS

\subsubsection{Long-term (18-24 month) outcomes}

For long-term measures, TORS was the optimal treatment based on MDASI instrument for any confidence level regarding the likelihood of postoperative ENE and PM (Figure 4). However, based on MDADI instrument, definitive RT became the optimal treatment when either postoperative ENE or PM are extremely likely ( $>90 \%)$ to occur. TORS was the optimal treatment if the likelihood of both postoperative events remained less than 70\%. According to DIGEST instrument, however, 
medRxiv preprint doi: https://doi.org/10.1101/2021.06.12.21258794; this version posted June 15, 2021. The copyright holder for this preprint (which was not certified by peer review) is the author/funder, who has granted medRxiv a license to display the preprint in perpetuity.

All rights reserved. No reuse allowed without permission.

definitive RT remained the optimal treatment even if either of the events was likely, at least, 25\%. In this case, TORS becomes the optimal treatment plan only if both events are extremely unlikely to occur $(<10 \%)$. Finally, in the absence of pre-therapy information about ENE or PM likelihood, TORS risk level is at $21 \%$ according to MDADI, and $97 \%$ according to DIGEST with TORS carrying no risk based on MDASI instrument.
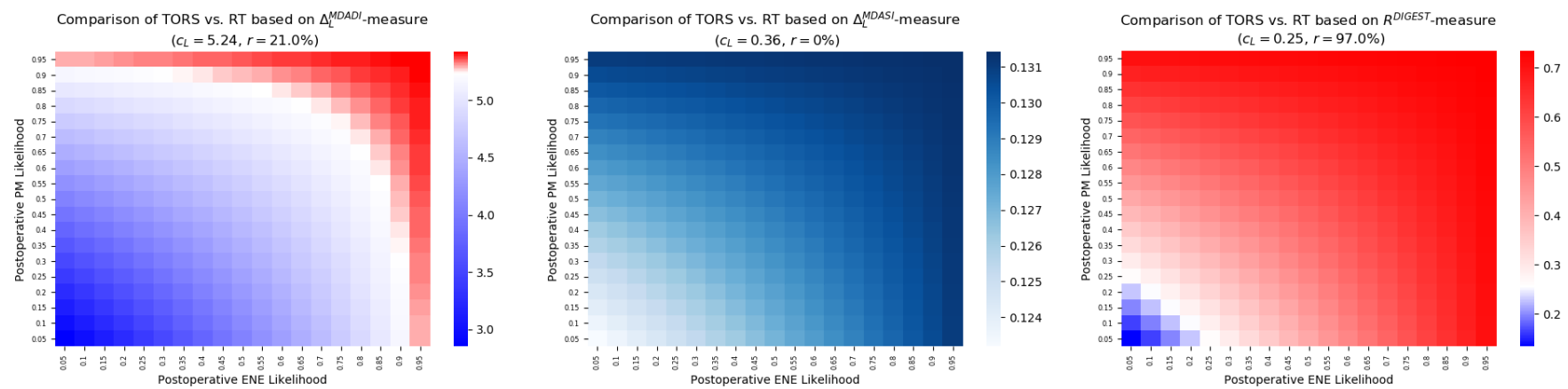

Figure 4: Expected deterioration in swallowing function due to TORS and definitive RT based on long-term measures (left) MDADI, (center) MDASI, (right) DIGEST. $\triangle_{L}^{M D A D I}$ : MDADI-based absolute short-term deterioration; $\Delta_{L}^{M D A S I}$ : MDASI-based absolute short-term deterioration; $\mathrm{R}^{\text {DIGEST }}$ : DIGEST-based absolute short-term deterioration in swallowing function; $c_{S}$ : cut-off value for TORS; and r: risk associated with TORS.

Table 3 summarizes the confidence level of postoperative events likelihood required to ensure TORS or definitive RT is the optimal treatment under the first scenario.

Table 3: Range of likelihoods required for TORS or definitive RT to become the optimal treatment under the first scenario. ENE: postoperative extranodal extension; PM: postoperative positive margin.

\begin{tabular}{|c|c|c|}
\hline Instrument/Measure & $\begin{array}{c}\text { Confidence level of postoperative events } \\
\text { for which TORS is optimal }\end{array}$ & $\begin{array}{c}\text { Confidence level of postoperative events for } \\
\text { which definitive RT is optimal }\end{array}$ \\
\hline \multicolumn{3}{|l|}{ MDADI } \\
\hline Short-term (3-6 mo) & - & Any likelihood associated with ENE and/or PM \\
\hline Long-term (18-24 mo) & When both ENE and PM have likelihood $<70 \%$ & If either of ENE or PM has a likelihood $>90 \%$ \\
\hline \multicolumn{3}{|l|}{ MDASI } \\
\hline Short-term (3-6 mo) & - & Any likelihood associated with ENE and/or PM \\
\hline Long-term (18-24 mo) & Any likelihood associated with ENE and/or PM & - \\
\hline \multicolumn{3}{|l|}{ DIGEST } \\
\hline Short-term (3-6 mo) & When both ENE and PM have likelihood $<40 \%$ & If either of ENE or PM has a likelihood $>75 \%$ \\
\hline Long-term (18-24 mo) & When both ENE and PM have likelihood $<10 \%$ & If either of ENE or PM has a likelihood $>25 \%$ \\
\hline
\end{tabular}

\subsection{TORS vs. definitive CRT (Scenario 2)}

\subsubsection{Short-term (3-6 month) outcomes}

When comparing TORS to definitive CRT using short-term measures, TORS was the optimal treatment based on both MDADI and MDASI instruments for any likelihoods associated with postoperative ENE and/or PM (Figure 5). This observation was evident from the related measure values reported in Table 2. Based on DIGEST instrument, the patient undergoing TORS will experience higher swallowing-related toxicity if the likelihood for any of the postoperative event is more than $80 \%$, thus making definitive CRT the optimal treatment in those cases. TORS remained the optimal treatment when both postoperative events have a likelihood of, at most, 55\%. Further, in the absence of pre-therapy information about ENE or PM likelihood, TORS risk level is at most $45 \%$ according to DIGEST, while it carries no risk according to the other instruments. 
medRxiv preprint doi: https://doi.org/10.1101/2021.06.12.21258794; this version posted June 15, 2021. The copyright holder for this preprint (which was not certified by peer review) is the author/funder, who has granted medRxiv a license to display the preprint in perpetuity. All rights reserved. No reuse allowed without permission.
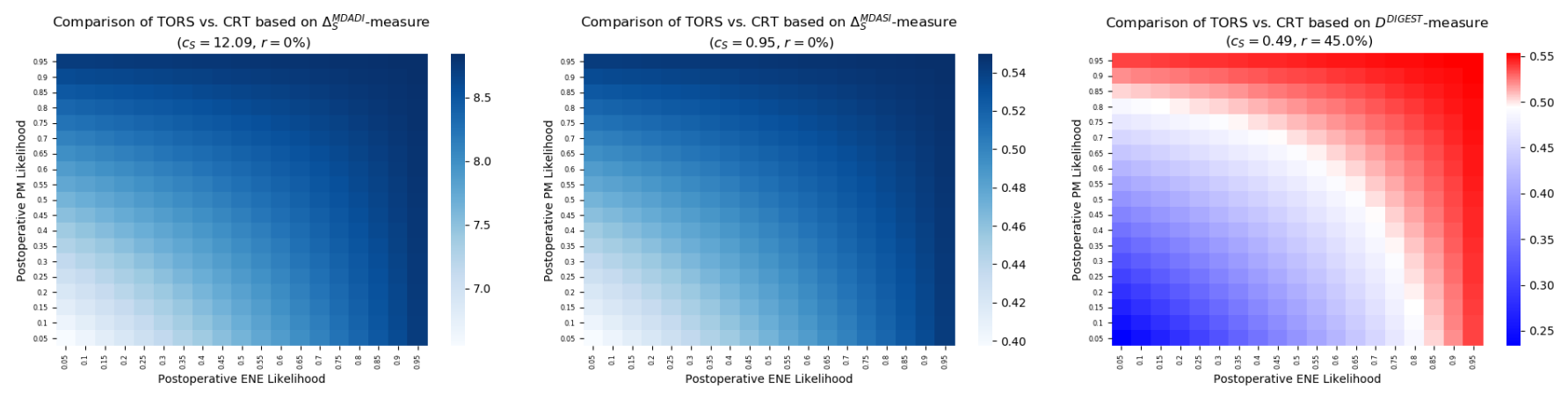

Figure 5: Expected deterioration in swallowing function due to TORS and definitive CRT based on short-term measures (left) MDADI, (center) MDASI, (right) DIGEST. $\triangle_{S}^{M D A D I}$ : MDADI-based absolute short-term deterioration; $\triangle_{S}^{M D A S I}$ : MDASI-based absolute short-term deterioration; $D^{\text {DIGEST }}$ : DIGEST-based absolute short-term deterioration in swallowing function; $c_{S}$ : cut-off value for TORS; and $r$ : risk associated with TORS.

\subsubsection{Long-term (18-24 month) outcomes}
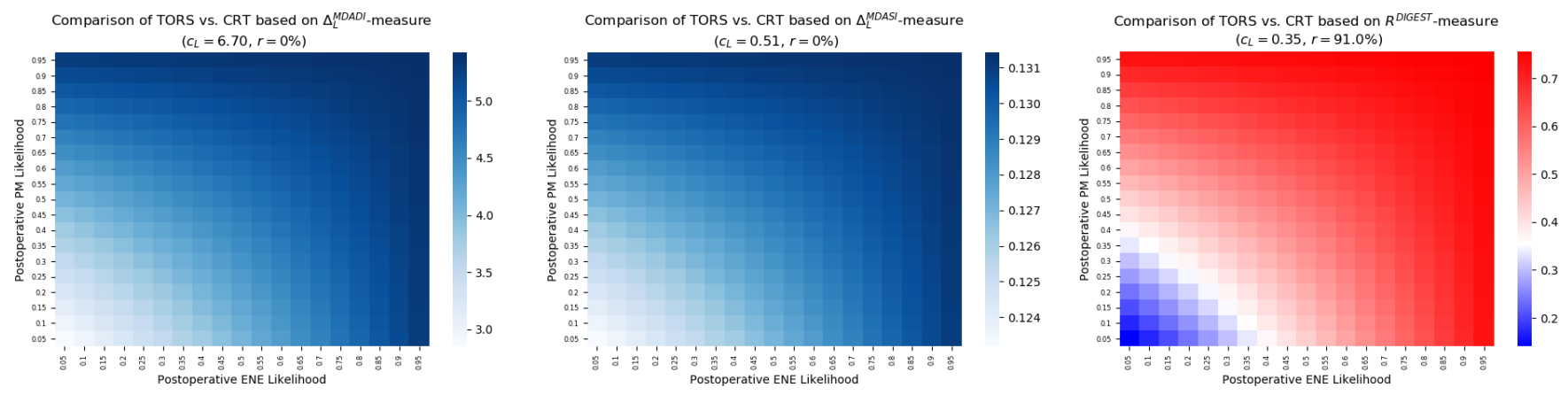

Figure 6: Expected deterioration in swallowing function due to TORS and definitive CRT based on long-term measures (left) MDADI, (center) MDASI, (right) DIGEST. $\triangle_{L}^{M D A D I}$ : MDADI-based absolute short-term deterioration; $\triangle_{L}^{M D A S I}$ : MDASI-based absolute short-term deterioration; $R^{\text {DIGEST }}$ : DIGEST-based absolute short-term deterioration in swallowing function; $c_{S}$ : cut-off value for TORS; and $r$ : risk associated with TORS.

For this scenario, the results of decision tree analysis for long-term measures were highly similar to those for the first scenario (Figure 6). In particular, TORS remained the optimal treatment based on both MDADI and MDASI instruments being insensitive to the likelihood of postoperative ENE or PM. However, according to DIGEST instrument, even moderate likelihood $(>40 \%)$ for either of postoperative events implies the superiority of definitive CRT over TORS. The latter becomes the optimal treatment when both postoperative events have a small likelihood $(<20 \%)$. Further, when no pretherapy information about the likelihoods is available, DIGEST assigns a risk level of $91 \%$ to TORS, while MDASI and MDASI indicate that there is no risk level for TORS (Figure 6).

A summary of the confidence level of postoperative events likelihoods required for the optimality of TORS and definitive CRT is given in Table 4.

Table 4: Range of likelihoods required for TORS or definitive CRT to become the optimal treatment under the second scenario. ENE: postoperative extranodal extension; PM: postoperative positive margin.

\begin{tabular}{|c|c|c|}
\hline Instrument/Measure & $\begin{array}{l}\text { Confidence level of postoperative events } \\
\text { for which TORS is optimal }\end{array}$ & $\begin{array}{c}\text { Confidence level of postoperative events for } \\
\text { which definitive CRT is optimal }\end{array}$ \\
\hline \multicolumn{3}{|l|}{ MDADI } \\
\hline Short-term (3-6 mo) & Any likelihood associated with ENE and/or PM & - \\
\hline Long-term (18-24 mo) & Any likelihood associated with ENE and/or PM & - \\
\hline \multicolumn{3}{|l|}{ MDASI } \\
\hline Short-term (3-6 mo) & Any likelihood associated with ENE and/or PM & - \\
\hline Long-term (18-24 mo) & Any likelihood associated with ENE and/or PM & - \\
\hline \multicolumn{3}{|l|}{ DIGEST } \\
\hline Short-term (3-6 mo) & When both ENE and PM have likelihood $<55 \%$ & If either of ENE or PM has a likelihood $>80 \%$ \\
\hline Long-term (18-24 mo) & When both ENE and PM have likelihood $<20 \%$ & If either of ENE or PM has a likelihood $>40 \%$ \\
\hline
\end{tabular}




\section{Discussion}

Since the approval of TORS by FDA as a minimally invasive surgical treatment protocol for HNC patients, there have been several studies reporting on the success of TORS as an option for treatment of early-stage oropharyngeal carcinomas due to its favorable oncologic outcomes and its potential to mitigate the toxicities incurred by patients in other surgical techniques or primary (chemo) radiation therapy. ${ }^{21-24}$ Consequently, TORS has been increasingly used for low- to intermediate-risk OPSCC patients having small-volume primary tumor and near-normal baseline function ${ }^{14}$. However, studies suggest a considerable percentage of patients that have undergone postoperative adjuvant (chemo) radiation therapy ${ }^{25-27}$, despite being theoretically believed to be candidate for surgical therapy alone. Put simply, the current data suggest that surgeons and radiation oncologists are decidedly poor at predicting whether a patient will require adjuvant treatment from pre-therapy exam, and thus many patients offered surgical resection are in fact being offered not TORS alone, but rather some unquantified probability of double- or triple-modality therapy (and the concomitant additional toxicities therefrom). This is primarily due to absence of extreme pre-surgical certitude regarding of post-TORS histopathological features, which makes it a challenging decision-making problem to choose between initial TORS or definitive non-surgical treatment protocols.

Operations research is an applied mathematics discipline focused on optimization of decision functions by rigorous statistical modeling. As one of the widely established toolsets in Operations Research, decision analysis provides an integrated framework to study decision-making scenarios that involve uncertain outcomes. The decision analysis model developed in this study incorporates the imputed pre-therapy physic-assessed statistical likelihood of the two major postoperative indicator events that trigger adjuvant therapy; namely pre-therapy physician-estimated probability of margin positivity and extranodal extension. Through quantifying post-therapy swallowing-related toxicities using well-established patient-reported and objective instruments, the model in this study captures the expected outcome of a treatment regimen which in comparison to the definitive radiotherapy's outcome can aid the clinical team in choosing the optimal treatment protocol. The results of this model can also be utilized to compute the risk level associated with TORS in terms of developing swallowing-related toxicities higher than definitive (chemo) radiation therapy in the absence of pre-therapy information on the likelihood of postoperative events that can trigger the need for adjuvant therapy.

The decision analysis model in this work has its own limitations. It currently relies on a single institutional database with a cohort of 257 patients. Bootstrapping was employed to mitigate the effects of small-size population allowing the model to make assumptions as "real-life" as possible. Further, expected-value decision analysis has its own disadvantages, namely the sensitivity to the probability values as well as measures. Sensitivity analysis was performed to determine the variation of TORS risk level as a function of the likelihood of postoperative events as well as associated quantified short-term and long-term toxicity of all treatment protocols.

Three observations are notable from the current analysis: 1) there are distinctly different optimum choices based on the probability of toxicity that differ whether radiotherapy-alone or chemoradiotherapy is the comparator for surgical treatment; 2) there are divergent optimum choice of therapy regarding subjective multi-symptom (MDASI), subjective swallowing (MDADI) or objective swallowing (DIGEST) is the toxicity metric of interest; 3) choice of therapy based on early (3-6 month) swallowing outcomes may not reflect the optimum therapy selection for later time-points (18-24 months).

Ultimately, the aim of this effort is to quantize decision making for HNC/OPSCC patients eligible for alternative treatment protocols. The vast majority of cases selected for definitive organ-reservation or surgical therapy (potentially followed by adjuvant radiotherapy) are typically made using heuristic physician-decision processes which appear to speciously high estimates of the potential for single-modality surgery. However, if advanced approaches such as improved standardized radiologic assessment ${ }^{28}$, AI-assisted imaging analysis, or risk-models ${ }^{29}$ could improve outcomes by bringing quantitative decision-support to surgeons and radiation oncologists. Further, this data serves to define preoperative assessment tools for decision support for future explorations.

\section{Conclusion}

Our models demonstrated optimal decision thresholds for selection of surgical +/- adjuvant therapy or organ preservation with (chemo)radiotherapy based on clinically-representative subjective and objective toxicity outcomes. The resultant thresholds for physician certainty for prediction of clinical risk features necessitating adjuvant therapy should be considered with these decision tools as a component of multi-disciplinary patient-centric therapy selection for early-stage oropharyngeal cancer patients. 
medRxiv preprint doi: https://doi.org/10.1101/2021.06.12.21258794; this version posted June 15, 2021. The copyright holder for this preprint (which was not certified by peer review) is the author/funder, who has granted medRxiv a license to display the preprint in perpetuity. All rights reserved. No reuse allowed without permission.

\section{References:}

1. Baskin RM, Boyce BJ, Amdur R, et al. Transoral robotic surgery for oropharyngeal cancer: Patient selection and special considerations. Cancer Manag Res. 2018;10:839-846. doi:10.2147/CMAR.S118891

2. Chaturvedi AK, Engels EA, Pfeiffer RM, et al. Human papillomavirus and rising oropharyngeal cancer incidence in the United States. J Clin Oncol. 2011;29(32):4294-4301. doi:10.1200/JCO.2011.36.4596

3. Institute NC. Cancer Statistics.

4. Institute NC. Head and Neck Cancers.

5. Jamal Z, Anjum F. Oropharyngeal Squamous Cell Carcinoma. StatPearls [Internet]. Published online 2020.

6. Lazarus CL, Ganz C, Ru M, Miles BA, Kotz T, Chai RL. Prospective instrumental evaluation of swallowing, tongue function, and QOL measures following transoral robotic surgery alone without adjuvant therapy. Head Neck. 2019;41(2):322-328. doi:10.1002/hed.25455

7. Rieger JM, Zalmanowitz JG, Li SYY, et al. Functional outcomes after surgical reconstruction of the base of tongue using the radial forearm free flap in patients with oropharyngeal carcinoma. Head Neck. 2007;29(11):1024-1032. doi:10.1002/hed.20623

8. O'Connell DA, Rieger J, Harris JR, et al. Swallowing function in patients with base of tongue cancers treated with primary surgery and reconstructed with a modified radial forearm free flap. Arch Otolaryngol - Head Neck Surg. 2008;134(8):857-864. doi:10.1001/archotol.134.8.857

9. Chia SH, Gross ND, Richmon JD. Surgeon experience and complications with transoral robotic surgery (TORS). Otolaryngol - Head Neck Surg (United States). 2013;149(6):885-892. doi:10.1177/0194599813503446

10. Hutcheson KA, Holsinger FC, Kupferman ME, Lewin JS. Functional outcomes after TORS for oropharyngeal cancer: a systematic review. Eur Arch Oto-Rhino-Laryngology. 2015;272(2):463-471. doi:10.1007/s00405-014$2985-7$

11. More YI, Tsue TT, Girod DA, et al. Functional swallowing outcomes following transoral robotic surgery vs primary chemoradiotherapy in patients with advanced-stage oropharynx and supraglottis cancers: Comment. Dysphagia. 2013;28(4):593-594. doi:10.1007/s00455-013-9478-5

12. Amit M, Hutcheson K, Zaveri J, et al. Patient-reported outcomes of symptom burden in patients receiving surgical or nonsurgical treatment for low-intermediate risk oropharyngeal squamous cell carcinoma: A comparative analysis of a prospective registry. Oral Oncol. 2019;91:13-20. doi:10.1016/j.oraloncology.2019.01.020

13. Heah H, Goepfert RP, Hutcheson KA, et al. Decreased gastrostomy tube incidence and weight loss after transoral robotic surgery for low- to intermediate-risk oropharyngeal squamous cell carcinoma. Head Neck.

2018;40(11):2507-2513. doi:10.1002/hed.25382

14. Hutcheson KA, Warneke CL, Yao CMKL, et al. Dysphagia after Primary Transoral Robotic Surgery with Neck Dissection vs Nonsurgical Therapy in Patients with Low- to Intermediate-Risk Oropharyngeal Cancer. JAMA Otolaryngol - Head Neck Surg. 2019;145(11):1053-1063. doi:10.1001/jamaoto.2019.2725

15. Hutcheson KA, Lewin JS, Barringer DA, et al. Late dysphagia after radiotherapy-based treatment of head and neck cancer. Cancer. 2012;118(23):5793-5799. doi:10.1002/cncr.27631

16. Chen AY, Frankowshi R, Bishop-Leone J, et al. The development and validation of a dysphagia-specific qualityof-life questionnaire for patients with head and neck cancer: The M. D. Anderson Dysphagia Inventory. Arch Otolaryngol - Head Neck Surg. 2001;127(7):870-876.

17. Rosenthal DI, Mendoza TR, Chambers MS, et al. Measuring head and neck cancer symptom burden: The development and validation of the M. D. Anderson symptom inventory, head and neck module. Head Neck. 2007;29(10):923-931. doi:10.1002/hed.20602

18. Goepfert RP, Lewin JS, Barrow MP, et al. Grading dysphagia as a toxicity of head and neck cancer: differences in severity classification based on MBS DIGEST and clinical CTCAE grades. Dysphagia. 2018;33(2):185-191.

19. James G, Witten D, Hastie T, Tibshirani R. An Introduction to Statistical Learning. Vol 112. Springer; 2013.

20. Sox HS, Blatt MA, Higgins MC, Marton KI. Medical decision making. Philadelphia: American College of 
medRxiv preprint doi: https://doi.org/10.1101/2021.06.12.21258794; this version posted June 15, 2021. The copyright holder for this preprint (which was not certified by peer review) is the author/funder, who has granted medRxiv a license to display the preprint in perpetuity.

All rights reserved. No reuse allowed without permission.

Physicians. Published online 2007.

21. Ling DC, Chapman B V, Kim J, et al. Oncologic outcomes and patient-reported quality of life in patients with oropharyngeal squamous cell carcinoma treated with definitive transoral robotic surgery versus definitive chemoradiation. Oral Oncol. 2016;61:41-46.

22. Lira RB, Kowalski LP. Robotic Head and Neck Surgery: Beyond TORS. Curr Oncol Rep. 2020;22(9):1-7.

23. Achim V, Bolognone RK, Palmer AD, et al. Long-term functional and quality-of-life outcomes after transoral robotic surgery in patients with oropharyngeal cancer. JAMA Otolaryngol $\backslash \&$ Neck Surg. 2018;144(1):18-27.

24. De Almeida JR, Li R, Magnuson JS, et al. Oncologic outcomes after transoral robotic surgery: a multi-institutional study. JAMA Otolaryngol $\backslash \&$ Neck Surg. 2015;141(12):1043-1051.

25. Sinclair CF, McColloch NL, Carroll WR, Rosenthal EL, Desmond RA, Magnuson JS. Patient-perceived and objective functional outcomes following transoral robotic surgery for early oropharyngeal carcinoma. Arch Otolaryngol $\backslash \&$ Neck Surg. 2011;137(11):1112-1116.

26. Hurtuk A, Agrawal A, Old M, Teknos TN, Ozer E. Outcomes of transoral robotic surgery: a preliminary clinical experience. Otolaryngol Neck Surg. 2011;145(2):248-253.

27. Weinstein GS, O’Malley BW, Cohen MA, Quon H. Transoral robotic surgery for advanced oropharyngeal carcinoma. Arch Otolaryngol $\backslash \&$ Neck Surg. 2010;136(11):1079-1085.

28. Faraji F, Aygun N, Coquia SF, et al. Computed tomography performance in predicting extranodal extension in HPV-positive oropharynx cancer. Laryngoscope. 2020;130(6):1479-1486.

29. Hararah MK, Stokes WA, Jones BL, et al. Nomogram for preoperative prediction of nodal extracapsular extension or positive surgical margins in oropharyngeal squamous cell carcinoma. Oral Oncol. 2018;83:73-80. 
medRxiv preprint doi: https://doi.org/10.1101/2021.06.12.21258794; this version posted June 15, 2021. The copyright holder for this preprint (which was not certified by peer review) is the author/funder, who has granted medRxiv a license to display the preprint in perpetuity.

All rights reserved. No reuse allowed without permission.

\section{Appendix A1: Computation of MDADI-based short-term and long-term scores}

Based on the responses from the patients treated via treatment approach X (i.e., TORS, D_RT, D_CRT, TORS+RT, TORS+CRT, as stated in Table 1, the absolute short- and long-term reductions in MDADI score were computed as

$$
\Delta_{S}^{M D A D I}(X)=\operatorname{MDADI}_{\text {baseline }}(X)-\operatorname{MDADI}_{3-6}(X),
$$

and

$$
\Delta_{L}^{M D A D I}(X)=\operatorname{MDADI}_{\text {baseline }}(X)-\operatorname{MDADI}_{18-24}(X),
$$

respectively, where $\operatorname{MDADI}_{\text {baseline }}(X), \operatorname{MDADI}_{3-6}(X)$, and $\operatorname{MDADI}_{12-24}(X)$ are the patient-reported MDADI scores prior to receiving treatment $X$, within 3-6 months, and within 18-24 months after receiving treatment $X$, respectively, for a given treatment $X$.

\section{Appendix A2: Computation of MDASI-based short-term and long-term scores}

Participating patients completed the MDASI-HN questionnaire before (baseline), within 3-6 month, and 18-24 months after therapy. The MDASI-based absolute short- and long-term increments for treatment approach X was computed as

$$
\Delta_{S}^{M D A S I}(X)=\operatorname{MDASI}_{3-6}(X)-\operatorname{MDASI}_{\text {baseline }}(X)
$$

and

$$
\Delta_{L}^{M D A D I}(X)=\operatorname{MDADI}_{18-24}(X)-\operatorname{MDADI}_{\text {baseline }}(X)
$$

respectively.

\section{Appendix A3: Computation of DIGEST-based short-term and long-term grades}

In this study, measures based on pre- and post-therapy DIGEST grades were employed. First, the DIGEST-based relative increment in the swallowing-related symptoms was defined as

$$
R^{D I G E S T}(X)=\frac{n_{L}(X)}{N_{L}(X)}
$$

where $n_{\mathrm{L}}(X)$ is the number of patients whose DIGEST grade increased within 18-24 months compared to their baseline grades. Also, $N_{\mathrm{L}}(X)$ is the number of patients for whom DIGEST grade was computed within 18-24 months after the therapy. Furthermore, the DIGEST-based relative short-term discomfort of treatment $X$ was defined as

$$
D^{D I G E S T}(X)=\frac{n_{\mathrm{S}}(X)}{N_{S}(X)}
$$

with $n_{\mathrm{S}}(X)$ being the number of patients whose DIGEST grade increased within 3-6 months compared to their baseline grades. $\mathrm{N}_{\mathrm{S}}(X)$ is defined analogously to $\mathrm{N}_{\mathrm{L}}(X)$ for the period of 3-6 months after treatment $X$. 
medRxiv preprint doi: https://doi.org/10.1101/2021.06.12.21258794; this version posted June 15, 2021. The copyright holder for this preprint (which was not certified by peer review) is the author/funder, who has granted medRxiv a license to display the preprint in perpetuity.

All rights reserved. No reuse allowed without permission.

\section{Appendix B: Sensitivity analysis for the likelihood of having significant postoperative tumor resection margin}

The heatmaps were also reproduced for extremely low and high values of the probability of having significant postoperative tumor resection margin $\left(p_{T M}^{+}\right)$in order to study its effect on the TORS risk level compared to definitive therapies.

\section{B1. TORS vs. definitive RT}

\section{B1.1. Short-term outcomes $\left(p_{T M}^{+}=0.1\right)$}
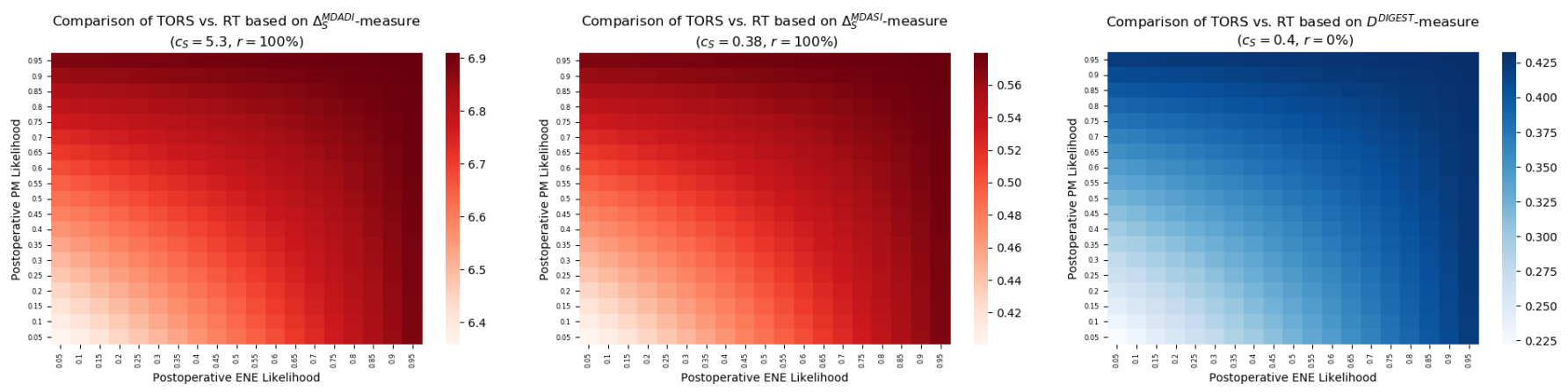

Figure B1: Expected deterioration in swallowing function due to TORS and definitive RT based on short-term measures (left) MDADI, (center)

MDASI, (right) DIGEST. $\triangle_{S}^{M D A D I}$ : MDADI-based absolute short-term deterioration; $\triangle_{S}^{M D A S I}$ : MDASI-based absolute short-term deterioration; $D^{D I G E S T}$ : DIGEST-based absolute short-term deterioration in swallowing function; $c_{S}$ : cut-off value for TORS; and $r$ : risk associated with TORS for $p_{T M}^{+}=0.1$

\section{B1.2. Short-term outcomes $\left(p_{T M}^{+}=0.9\right)$}
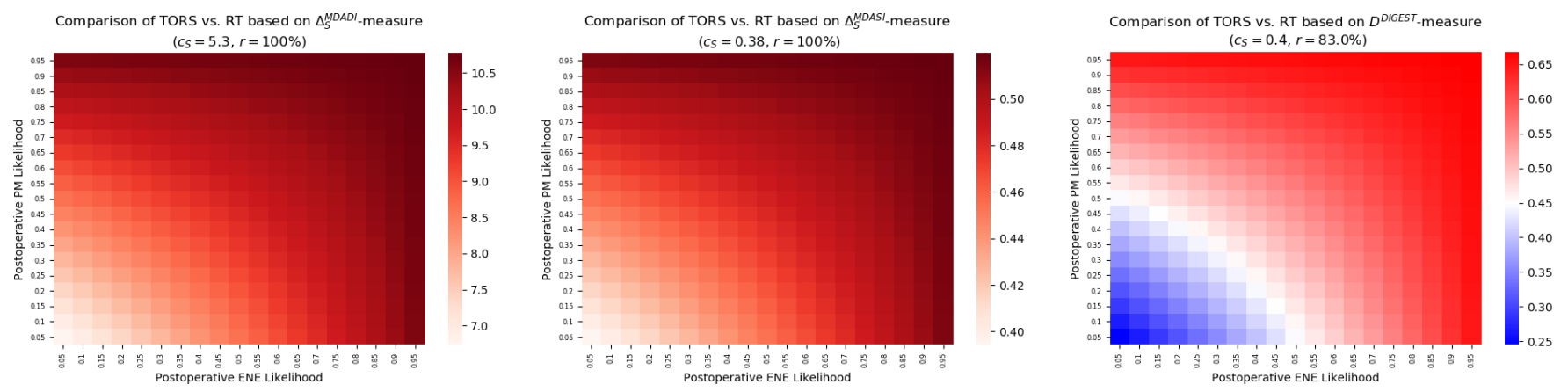

Figure B2: Expected deterioration in swallowing function due to TORS and definitive RT based on short-term measures (left) MDADI, (center)

MDASI, (right) DIGEST. $\triangle_{S}^{M D A D I}$ : MDADI-based absolute short-term deterioration; $\triangle_{S}^{M D A S I}$ : MDASI-based absolute short-term deterioration; $D^{\text {DIGEST }}$ : DIGEST-based absolute short-term deterioration in swallowing function; $c_{S}$ : cut-off value for TORS; and $r$ : risk associated with TORS for $p_{T M}^{+}=0.9$.

B1.3. Long-term outcomes $\left(p_{T M}^{+}=0.1\right)$
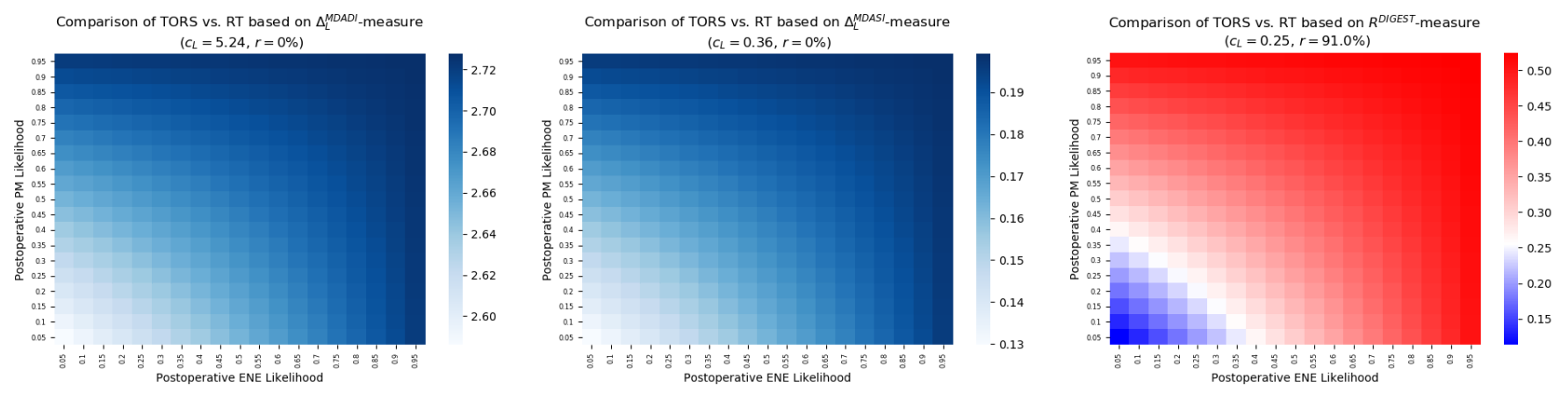
medRxiv preprint doi: https://doi.org/10.1101/2021.06.12.21258794; this version posted June 15, 2021. The copyright holder for this preprint (which was not certified by peer review) is the author/funder, who has granted medRxiv a license to display the preprint in perpetuity.

All rights reserved. No reuse allowed without permission.

Figure B3: Expected deterioration in swallowing function due to TORS and definitive RT based on long-term measures (left) MDADI, (center)

MDASI, (right) DIGEST. $\triangle_{S}^{M D A D I}$ : MDADI-based absolute short-term deterioration; $\triangle_{S}^{M D A S I}$ : MDASI-based absolute short-term deterioration; $D^{D I G E S T}$ : DIGEST-based absolute short-term deterioration in swallowing function; $c_{S}$ : cut-off value for TORS; and $r$ : risk associated with TORS for

$$
p_{T M}^{+}=0.1 \text {. }
$$

\section{B1.4. Long-term outcomes $\left(p_{T M}^{+}=0.9\right)$}
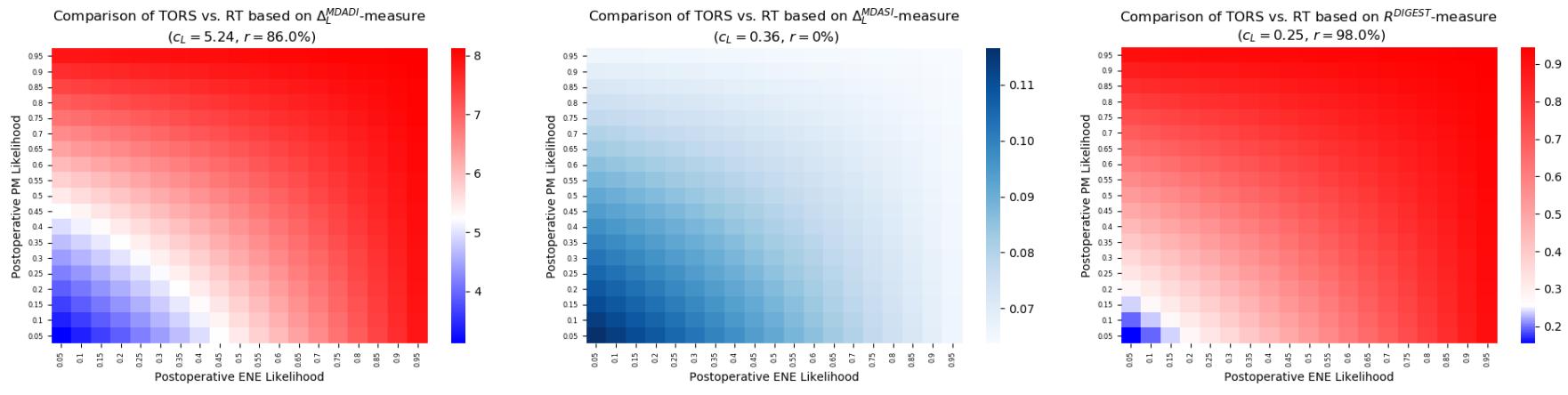

Figure B4: Expected deterioration in swallowing function due to TORS and definitive RT based on short-term measures (left) MDADI, (center) MDASI, (right) DIGEST. $\triangle_{S}^{M D A D I}$ : MDADI-based absolute short-term deterioration; $\triangle_{S}^{M D A S I}$ : MDASI-based absolute short-term deterioration; $D^{\text {DIGEST }}$ : DIGEST-based absolute short-term deterioration in swallowing function; $c_{S}$ : cut-off value for TORS; and $r$ : risk associated with TORS for $p_{T M}^{+}=0.9$.

Table B1 summarizes the risk level variation associated with TORS (when compared to definitive RT), as a function of tumor resection margin, in the absence of pre-therapy information about the postoperative ENE and PM likelihoods.

Table B1: Sensitivity of risk level associated with TORS (vs. definitive RT) as a function of postoperative tumor resection margin. $p_{T M}^{+}$: probability of having tumor resection margin $>2 \mathrm{~mm} ; r$ : TORS risk level; (I): Insensitive to $p_{T M}^{+} ;(\mathrm{HS})$ : Highly sensitive to $p_{T M}^{+} ; ;(\mathrm{LS})$ : Low sensitive to $p_{T M}^{+}$.

\begin{tabular}{lccc}
\hline & $\boldsymbol{p}_{\boldsymbol{T M}}^{+} \mathbf{= 5 0 \%}$ & \multicolumn{2}{c}{ Risk sensitivity to $\boldsymbol{p}_{\boldsymbol{T M}}^{+}$} \\
\hline Short-term toxicity level & $65 \% \leq r \leq 100 \%$ & MDADI & $r=100 \%$ (I) \\
& TORS carries high risk & MDASI & $r=100 \%$ (I) \\
& (conclusive across all instruments) & DIGEST & $r \leq 83 \%$ (HS) \\
\hline Long-term toxicity level & $0 \% \leq r \leq 97 \%$ & MDADI & $r \leq 86 \%$ (HS) \\
& TORS risk varies based on the instrument & MDASI & $r=0 \%$ (I) \\
& (inconclusive across all instruments) & DIGEST & $91 \% \leq r \leq 98 \%$ (I) \\
\hline
\end{tabular}

\section{B2. TORS vs. definitive CRT}

\section{B2.1. Short-term outcomes $\left(p_{T M}^{+}=0.1\right)$}
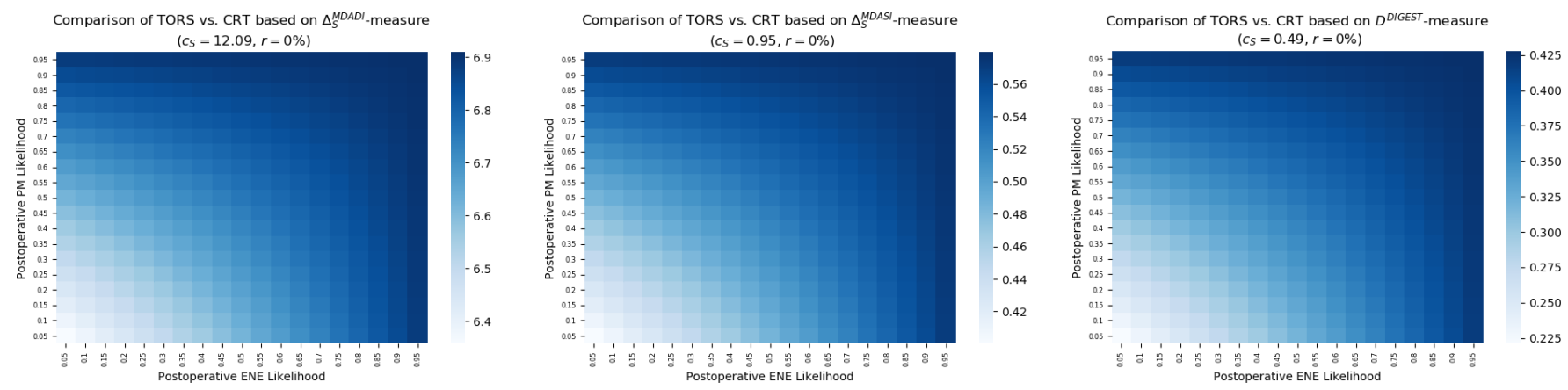
medRxiv preprint doi: https://doi.org/10.1101/2021.06.12.21258794; this version posted June 15, 2021. The copyright holder for this preprint (which was not certified by peer review) is the author/funder, who has granted medRxiv a license to display the preprint in perpetuity.

All rights reserved. No reuse allowed without permission.

Figure B5: Expected deterioration in swallowing function due to TORS and definitive CRT based on short-term measures (left) MDADI, (center)

MDASI, (right) DIGEST. $\triangle_{S}^{M D A D I}$ : MDADI-based absolute short-term deterioration; $\triangle_{S}^{M D A S I}$ : MDASI-based absolute short-term deterioration;

$D^{D I G E S T}$ : DIGEST-based absolute short-term deterioration in swallowing function; $c_{S}$ : cut-off value for TORS; and $r$ : risk associated with TORS for

$$
p_{T M}^{+}=0.1 \text {. }
$$

\section{B2.2. Short-term outcomes $\left(p_{T M}^{+}=0.9\right)$}
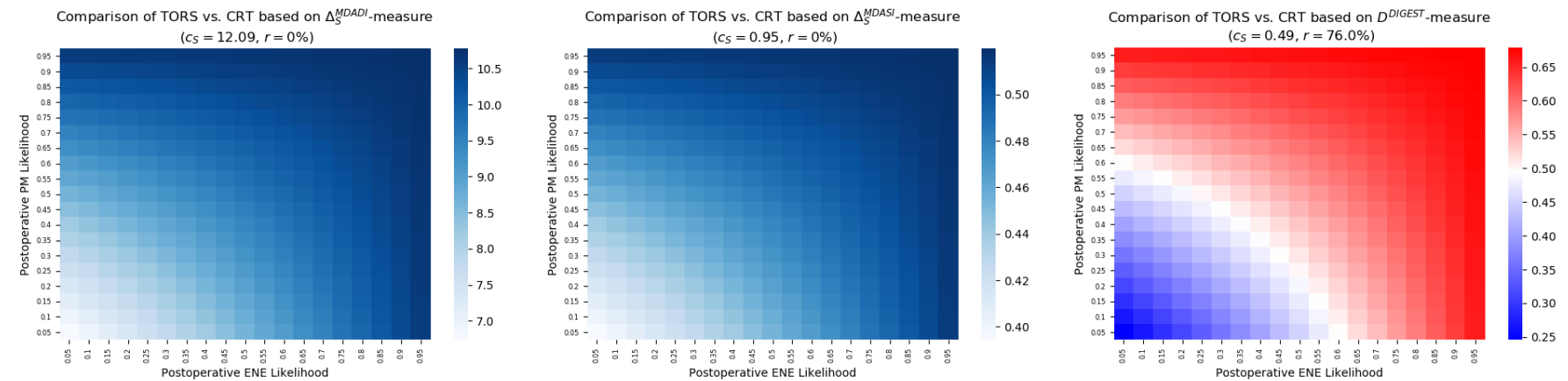

Figure B6: Expected deterioration in swallowing function due to TORS and definitive CRT based on short-term measures (left) MDADI, (center)

MDASI, (right) DIGEST. $\triangle_{S}^{M D A D I}$ : MDADI-based absolute short-term deterioration; $\triangle_{S}^{M D A S I}$ : MDASI-based absolute short-term deterioration; $D^{\text {DIGEST }}$ : DIGEST-based absolute short-term deterioration in swallowing function; $c_{S}$ : cut-off value for TORS; and $r$ : risk associated with TORS for $p_{T M}^{+}=0.9$.

\section{B2.3. Long-term outcomes $\left(p_{T M}^{+}=\mathbf{0 . 1}\right)$}
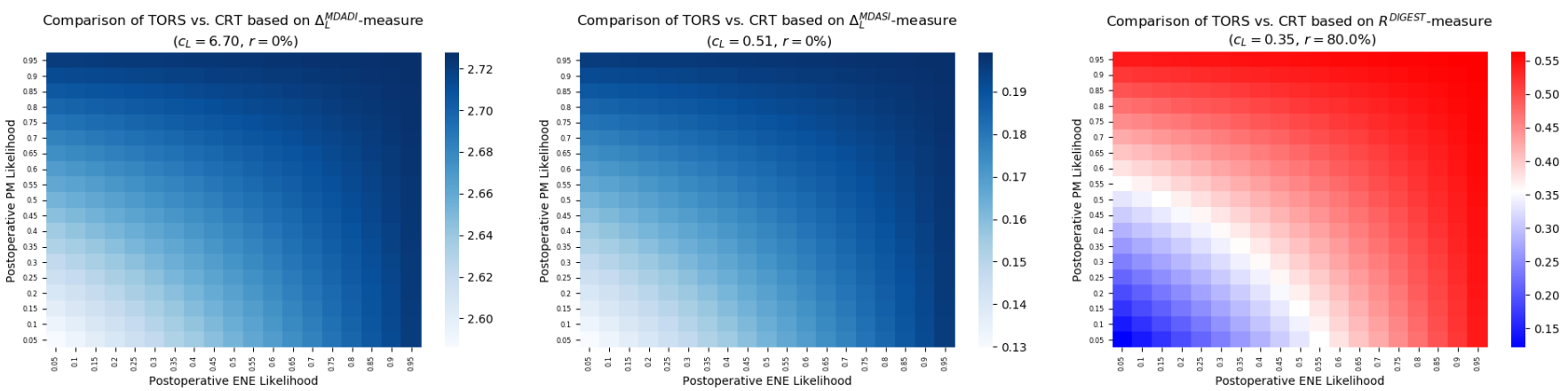

Figure B7: Expected deterioration in swallowing function due to TORS and definitive CRT based on long-term measures (left) MDADI, (center)

MDASI, (right) DIGEST. $\triangle_{S}^{M D A D I}$ : MDADI-based absolute short-term deterioration; $\triangle_{S}^{M D A S I}$ : MDASI-based absolute short-term deterioration; $D^{\text {DIGEST }}$ : DIGEST-based absolute short-term deterioration in swallowing function; $c_{S}$ : cut-off value for TORS; and $r$ : risk associated with TORS for $p_{T M}^{+}=0.1$.

\section{B2.4. Long-term outcomes $\left(p_{T M}^{+}=0.9\right)$}
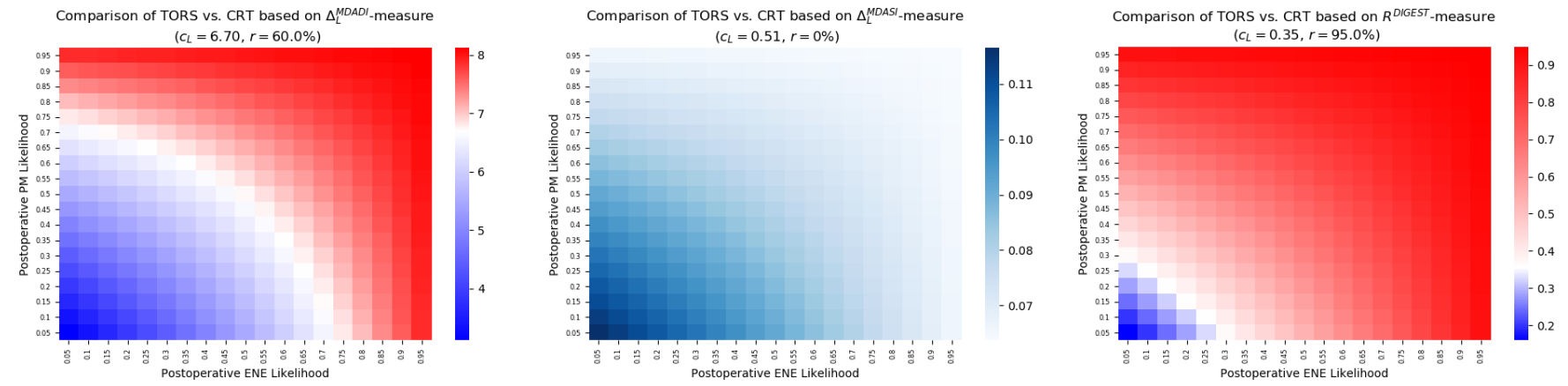

Figure B8: Expected deterioration in swallowing function due to TORS and definitive CRT based on long-term measures (left) MDADI, (center)

MDASI, (right) DIGEST. $\triangle_{S}^{M D A D I}$ : MDADI-based absolute short-term deterioration; $\Delta_{S}^{M D A S I}$ : MDASI-based absolute short-term deterioration; $D^{D I G E S T}$ : DIGEST-based absolute short-term deterioration in swallowing function; $c_{S}$ : cut-off value for TORS; and $r$ : risk associated with TORS for $p_{T M}^{+}=0.9$. 
medRxiv preprint doi: https://doi.org/10.1101/2021.06.12.21258794; this version posted June 15, 2021. The copyright holder for this preprint (which was not certified by peer review) is the author/funder, who has granted medRxiv a license to display the preprint in perpetuity.

All rights reserved. No reuse allowed without permission.

Table B2 summarizes the risk level variation associated with TORS (when compared to definitive CRT), as a function of tumor resection margin, in the absence of pre-therapy information about the postoperative ENE and PM likelihoods.

Table B2: Sensitivity of risk level associated with TORS (vs. definitive CRT) as a function of postoperative tumor resection margin. $p_{T M}^{+}$: probability of having tumor resection margin $>2 \mathrm{~mm} ; r$ : TORS risk level; (I): Insensitive to $p_{T M}^{+}$; (HS): Highly sensitive to $p_{T M}^{+}$; (RS) Relatively sensitive to $p_{T M}^{+} ;(\mathrm{LS})$ : Low sensitive to $p_{T M}^{+}$;

\begin{tabular}{lclc}
\hline & $\boldsymbol{p}_{\boldsymbol{T M}}^{+} \mathbf{= 5 0 \%}$ & \multicolumn{2}{c}{ Risk sensitivity to $\boldsymbol{p}_{\boldsymbol{T M}}^{+}$} \\
\hline Short-term toxicity level & $0 \% \leq r \leq 45 \%$ & MDADI & $r=0 \%$ (I) \\
& TORS carries average risk & MDASI & $r=0 \%$ (I) \\
& (almost conclusive across all instruments) & DIGEST & $0 \% \leq r \leq 76 \%$ (LS) \\
\hline Long-term toxicity level & $0 \% \leq r \leq 91 \%$ & MDADI & $0 \% \leq r \leq 60 \%$ (HS) \\
& TORS risk varies based on the instrument & MDASI & $r=0 \%$ (I) \\
& (inconclusive across all instruments) & DIGEST & $80 \% \leq r \leq 95 \%$ (LS) \\
\hline
\end{tabular}


medRxiv preprint doi: https://doi.org/10.1101/2021.06.12.21258794; this version posted June 15, 2021. The copyright holder for this preprint (which was not certified by peer review) is the author/funder, who has granted medRxiv a license to display the preprint in perpetuity.

All rights reserved. No reuse allowed without permission.

\section{Appendix C: DIGEST baseline grades evolution within 3-6 and 18-24 months}

Table C1: The evolution of DIGEST baseline grades within 3-6 moths and within 18-24 months post therapy.

\begin{tabular}{|c|c|c|c|c|c|c|}
\hline \multirow{2}{*}{\multicolumn{2}{|c|}{ RT }} & \multicolumn{5}{|c|}{ Within 3-6 months } \\
\hline & & 0 & 1 & 2 & 3 & 4 \\
\hline \multirow{5}{*}{$\begin{array}{l}\mathscr{\Xi} \\
\stackrel{\Xi}{\Xi} \\
\tilde{\Xi} \\
\mathscr{D}\end{array}$} & 0 & 8 & 6 & 1 & & \\
\hline & 1 & 3 & 2 & 3 & & \\
\hline & 2 & & & & & \\
\hline & 3 & & & & & \\
\hline & 4 & & & & & \\
\hline
\end{tabular}

(a)

\begin{tabular}{|c|c|c|c|c|c|c|}
\hline \multirow{2}{*}{\multicolumn{2}{|c|}{ CRT }} & \multicolumn{5}{|c|}{ Within 3-6 months } \\
\hline & & 0 & 1 & 2 & 3 & 4 \\
\hline \multirow{5}{*}{ 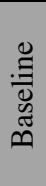 } & 0 & 50 & 35 & 14 & 4 & \\
\hline & 1 & 7 & 3 & 5 & 1 & \\
\hline & 2 & 14 & 5 & & & \\
\hline & 3 & & & & 1 & \\
\hline & 4 & & & & & \\
\hline
\end{tabular}

(c)

\begin{tabular}{|c|c|c|c|c|c|c|}
\hline \multicolumn{2}{|c|}{ TORS+RT } & \multicolumn{5}{|c|}{ Within 3-6 months } \\
\cline { 2 - 7 } & 0 & 1 & 2 & 3 & 4 \\
\hline \multirow{3}{*}{$\approx$} & 0 & 3 & 8 & 2 & & \\
\cline { 2 - 7 } & 1 & & 2 & & 1 & \\
\cline { 2 - 7 } & 2 & & & & & \\
\cline { 2 - 7 } & 3 & & & & & \\
\cline { 2 - 7 } & 4 & & & & & \\
\hline
\end{tabular}

(e)

\begin{tabular}{|c|c|c|c|c|c|c|}
\hline \multirow{2}{*}{\multicolumn{2}{|c|}{ TORS+CRT }} & \multicolumn{5}{|c|}{ Within 3-6 months } \\
\hline & & 0 & 1 & 2 & 3 & 4 \\
\hline \multirow{5}{*}{$\begin{array}{l}\stackrel{\Xi}{\Xi} \\
\stackrel{\Xi}{\Xi} \\
\mathscr{\varpi}\end{array}$} & 0 & 4 & 3 & 1 & & \\
\hline & 1 & 1 & & & & \\
\hline & 2 & & & 1 & & \\
\hline & 3 & & & & & \\
\hline & 4 & & & & & \\
\hline
\end{tabular}

(g)

\begin{tabular}{|c|c|c|c|c|c|c|}
\hline \multirow{2}{*}{\multicolumn{2}{|c|}{ TORS }} & \multicolumn{5}{|c|}{ Within 3-6 months } \\
\hline & & 0 & 1 & 2 & 3 & 4 \\
\hline \multirow{5}{*}{ 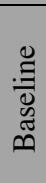 } & 0 & 11 & 5 & & & \\
\hline & 1 & 3 & 4 & & & \\
\hline & 2 & 1 & & & & \\
\hline & 3 & & & & & \\
\hline & 4 & & & & & \\
\hline
\end{tabular}

(i)

\begin{tabular}{|c|c|c|c|c|c|c|}
\hline \multicolumn{2}{|c|}{ RT } & \multicolumn{5}{|c|}{ Within 18-24 months } \\
\cline { 2 - 7 } & 0 & 1 & 2 & 3 & 4 \\
\hline \multirow{3}{*}{$\underset{\Xi}{\tilde{\Xi}}$} & 0 & 3 & 2 & 1 & & \\
\cline { 2 - 7 } & 1 & 3 & 2 & & & \\
\cline { 2 - 7 } & 2 & & & & & \\
\cline { 2 - 7 } & 3 & & & & & \\
\cline { 2 - 7 } & 4 & & & & & \\
\hline
\end{tabular}

(b)

\begin{tabular}{|c|c|c|c|c|c|c|}
\hline \multicolumn{2}{|c|}{ CRT } & \multicolumn{5}{|c|}{ Within 18-24 months } \\
\cline { 2 - 8 } & 0 & 1 & 2 & 3 & 4 \\
\hline \multirow{3}{*}{} & 0 & 34 & 15 & 4 & 1 & \\
\cline { 2 - 7 } & 1 & 3 & 6 & 2 & 1 & \\
\cline { 2 - 7 } & 2 & & & & & \\
\cline { 2 - 7 }$\oplus$ & 3 & & & & & \\
\cline { 2 - 7 } & 4 & & & & & \\
\hline
\end{tabular}

(d)

\begin{tabular}{|c|c|c|c|c|c|c|}
\hline \multicolumn{2}{|c|}{ TORS+RT } & \multicolumn{5}{|c|}{ Within 18-24 months } \\
\cline { 2 - 7 } & 0 & 1 & 2 & 3 & 4 \\
\hline \multirow{3}{*}{$\doteq$} & 0 & & 3 & 3 & & \\
\cline { 2 - 7 } & 1 & & & 1 & & \\
\cline { 2 - 7 } & 2 & & & & & \\
\cline { 2 - 7 } & 3 & & & & & \\
\cline { 2 - 7 } & 4 & & & & & \\
\hline
\end{tabular}

(f)

\begin{tabular}{|c|c|c|c|c|c|c|}
\hline \multicolumn{2}{|c|}{ TORS+CRT } & \multicolumn{5}{|c|}{ Within 18-24 months } \\
\cline { 2 - 7 } & 0 & 1 & 2 & 3 & 4 \\
\hline \multirow{4}{*}{$\Xi$} & 0 & 2 & 2 & 1 & & \\
\cline { 2 - 7 } & 1 & & 1 & & & \\
\cline { 2 - 7 } & 2 & & & & & \\
\cline { 2 - 7 } & 3 & & & & & \\
\cline { 2 - 7 } & 4 & & & & & \\
\hline
\end{tabular}

(h)

\begin{tabular}{|c|c|c|c|c|c|c|}
\hline \multirow{2}{*}{\multicolumn{2}{|c|}{ TORS }} & \multicolumn{5}{|c|}{ Within $18-24$ months } \\
\hline & & 0 & 1 & 2 & 3 & 4 \\
\hline \multirow{5}{*}{$\begin{array}{l}\stackrel{\Xi}{\Xi} \\
\bar{\Xi} \\
\mathscr{\Xi}\end{array}$} & 0 & 8 & 1 & & & \\
\hline & 1 & 2 & 1 & & & \\
\hline & 2 & & & & & \\
\hline & 3 & & & & & \\
\hline & 4 & & & & & \\
\hline
\end{tabular}

(j) 